\title{
Approximal Attrition and Permanent Tooth Crown Size in a Romano-British Population
}

\author{
A. H. Brook, * C. Underhill, L. K. Foo, M. Hector \\ School of Clinical Dentistry, Sheffield, and St Bartholomews and The London Dental School, \\ London, United Kingdom
}

\begin{abstract}
The aim was to measure mesiodistal crown size of both sexes in different age groups of a well characterised Romano-British population to determine the progressive effects of approximal attrition. From the collection in the British Museum of RomanoBritish skeletons excavated from Poundbury, aged and sexed by Museum staff on established criteria, two samples were selected randomly from those with intact permanent dentitions. The first examiner measured the teeth of 30 males and 30 females aged 14-24 years and the second examiner those of 59 males and 51 females distributed across the four age groups, namely 14-24, $25-34,35-45$, over 45 years. The mesiodistal diameter of each permanent tooth was measured on two separate occasions and the mean for each tooth type in each age group calculated. Differences were explored with two sample t-tests and multiple regression analysis. The intra-operator reproducibility for difference tooth types ranged from $r=0.92$ to $r=0.99$ and for inter-operator
\end{abstract}

In studying variation between populations tooth crown size is a valuable parameter of dental development (Keiser, 1990). Crown size is a continuous variable, which is multifactorially determined by both genetic and environmental factors (Brook, 1984). However, in seeking to determine tooth crown size in ancient populations, extensive attrition is a complicating factor. Attrition may vary from one population to another and in different periods of time (Molnar, 1971; Brothwell, 1989). Archeological populations appear to show a more regular increase in attrition with age than do modern populations with males tending to have higher attrition scores than females (Solheim, 1998).

Therefore, in an earlier population to establish tooth size and to investigate the progress of attrition it is necessary to have sufficient suitable material for various age groups and for both sexes. The Romano-British skeletal material from Poundbury, Dorset, United Kingdon, fulfils these requirements.

This study aimed to determine the initial mesiodistal tooth crown size and to measure the extent of progressive approximal attrition by determining mesiodistal crown dimensions in different age groups in this Romano-British sample. reproducibility from $r=0.74$ to $r=0.99$. In the youngest age group males had larger teeth than females with this difference being statistically significant for most tooth types. There was a pattern of decreasing tooth size over the four age groups, with males more affected than females. Different tooth types showed different reductions, the greatest being in upper and lower incisors and upper first molars and the least in lower second molars, upper second molars and third molars. The average total arch length reduction estimated by two different methods between aged groups 1 and 4 was 10.0 $\mathrm{mm}$ in the upper jaw and $6.4 \mathrm{~mm}$ in the lower jaw. Thus, in this Romano-British sample all tooth types showed reduction in mesiodistal diameter with increasing age, the extent varying between the sexes, the jaws and tooth types. From comparable studies, this approximal attrition was slightly greater than for mediaeval Swedes and considerably greater than modern Swedes and other Caucasians. Dental Anthropology 2006;19(1):23-28.

\section{MATERIALS AND METHODS}

Excavation of a Romano-British Christian cemetery, which was in use from AD 200-400, provided the material used in this study. The excavated skeletons of this homogeneous population are housed in the British Museum (Natural History), London. The sex determination and age estimation of 650 adult specimens had been carried out by staff of the British Museum. To estimate age at death the methods of Brothwell (1963) and Miles (1963a,b) were applied.

Adult males $(n=310)$ and adult females $(n=339)$ had been placed in the four age groups of 14-24 years, 25-34 years, 35-45 years, and over 45 years. Skulls for the current study were selected from those with intact or nearly intact dentitions using random number tables.

For the tooth size study 30 male and 30 female skulls

*Correspondence to: A. H. Brook, School of Dental Studies, Edwards Building, University of Liverpool, Pembroke Place, Liverpool L69 3GN, United Kingdom. E-mail: a.h.brook@liverpool.ac.uk 
TABLE 1. The number of skulls measured in each age group by sex

\begin{tabular}{|c|c|c|c|c|c|c|c|}
\hline & & \multicolumn{6}{|c|}{ Examiner 2} \\
\hline \multirow{2}{*}{\multicolumn{2}{|c|}{$\begin{array}{l}\text { Examiner } 1 \\
14-24 \text { years }\end{array}$}} & \multirow{2}{*}{\multicolumn{2}{|c|}{$14-24$ yrs }} & \multirow{3}{*}{$\frac{25-34 \mathrm{yrs}}{20}$} & \multicolumn{3}{|c|}{ Age Groups } \\
\hline & & & & & \multirow{2}{*}{$\frac{35-45 \text { yrs }}{16}$} & \multirow{2}{*}{$\frac{\text { Over } 45 \text { yrs }}{13}$} & \multirow{2}{*}{$\begin{array}{c}\text { Total } \\
59\end{array}$} \\
\hline Male & 30 & Male & 10 & & & & \\
\hline Female & 30 & Female & 12 & 17 & 13 & 9 & 51 \\
\hline Total & 60 & Total & 22 & 37 & 29 & 22 & 110 \\
\hline
\end{tabular}

were selected from the youngest age group and were measured by examiner one (LKF).

For the attrition study approximately equal numbers were randomly selected from each of the four age groups (Table 1) and were measured by examiner two (CAU).

Excluded from the study were teeth with caries or fractures involving an approximal surface, hypoplasia, rotations, or gross supragingival calculus. The mesiodistal diameters of the teeth were measured using dial calipers (Mitutuyo, Japan) and the criteria of Moorrees et al. (1957). Each dentition was measured on a second occasion several days later without access to the initial measurement. The mean of the two measurements was then used in the results.

Before commencement of the study the two examiners underwent training. The reproducibility was determined by remeasurement of 20 skulls selected using a random number taken on three occasions over 10 weeks. The intra-operator reproducibility for different tooth types ranged from $r=0.92$ to $r=0.99$. Inter-operator reproducibility ranged from $r=0.74$ to $r$ $=0.99$.

For the main study, the differences between mean measurements in each age group were examined for statistical significance using two sample t-tests. In order to take into account fluctuations across age groups related to numbers in each cell and sex differences, three-way multiple regression was also carried out for all individual teeth.

TABLE 2. The mesiodistal crown diameters obtained by two examiners obtained for 2 samples from age group ${ }^{1}$

\begin{tabular}{|c|c|c|c|c|c|c|c|c|c|c|c|c|}
\hline \multirow[b]{3}{*}{ Tooth } & \multicolumn{6}{|c|}{ Male } & \multicolumn{6}{|c|}{ Female } \\
\hline & \multicolumn{3}{|c|}{ Examiner 1} & \multicolumn{3}{|c|}{ Examiner 2} & \multicolumn{3}{|c|}{ Examiner 1} & \multicolumn{3}{|c|}{ Examiner 2} \\
\hline & $\mathrm{n}$ & $\bar{x}$ & sd & $\mathrm{n}$ & $\bar{x}$ & $\mathrm{sd}$ & $\mathrm{n}$ & $\bar{x}$ & sd & $\mathrm{n}$ & $\bar{x}$ & sd \\
\hline U1 & 24 & 8.41 & 0.48 & 16 & 8.43 & 0.32 & 30 & 8.15 & 0.45 & 17 & 7.80 & 0.34 \\
\hline U2 & 42 & 6.64 & 0.56 & 19 & 6.57 & 0.40 & 49 & 6.23 & 0.53 & 19 & 6.43 & 0.37 \\
\hline U3 & 49 & 7.63 & 0.38 & 20 & 7.60 & 0.33 & 51 & 7.28 & 0.40 & 17 & 7.28 & 0.22 \\
\hline U4 & 50 & 6.50 & 0.49 & 19 & 6.48 & 0.35 & 47 & 6.28 & 0.40 & 17 & 6.26 & 0.29 \\
\hline U5 & 44 & 6.39 & 0.45 & 19 & 6.16 & 0.44 & 40 & 6.10 & 0.36 & 19 & 6.05 & 0.28 \\
\hline U6 & 47 & 10.05 & 0.66 & 20 & 9.94 & 0.45 & 44 & 9.66 & 0.40 & 24 & 9.45 & 0.40 \\
\hline U7 & 45 & 9.35 & 0.39 & 21 & 9.41 & 0.59 & 45 & 9.08 & 0.47 & 23 & 9.11 & 0.59 \\
\hline U8 & 37 & 8.37 & 0.78 & 13 & 8.77 & 0.95 & 31 & 8.54 & 0.89 & 14 & 8.58 & 0.78 \\
\hline L1 & 14 & 5.15 & 0.37 & 22 & 5.11 & 0.24 & 23 & 4.99 & 0.36 & 19 & 4.96 & 0.25 \\
\hline L2 & 26 & 5.83 & 0.43 & 21 & 5.77 & 0.33 & 36 & 5.55 & 0.36 & 20 & 5.53 & 0.37 \\
\hline L3 & 41 & 6.63 & 0.48 & 20 & 6.68 & 0.32 & 46 & 6.29 & 0.37 & 20 & 6.30 & 0.21 \\
\hline L4 & 43 & 6.73 & 0.51 & 19 & 6.65 & 0.34 & 52 & 6.54 & 0.40 & 21 & 6.37 & 0.30 \\
\hline L5 & 42 & 6.64 & 0.50 & 18 & 6.63 & 0.35 & 43 & 6.48 & 0.47 & 23 & 6.51 & 0.38 \\
\hline L6 & 47 & 11.15 & 0.61 & 17 & 10.99 & 0.50 & 50 & 10.60 & 0.54 & 24 & 10.53 & 0.34 \\
\hline L7 & 45 & 10.43 & 0.63 & 20 & 10.49 & 0.38 & 51 & 10.12 & 0.71 & 20 & 10.16 & 0.54 \\
\hline L8 & 32 & 10.31 & 0.77 & 14 & 10.58 & 0.77 & 37 & 9.85 & 0.97 & 13 & 10.20 & 0.52 \\
\hline
\end{tabular}

${ }^{1} \mathrm{n}=$ number of teeth measured

$\overline{\mathrm{x}}=$ average mesiodistal tooth diameter $(\mathrm{mm})$

$\mathrm{sd}=$ standard deviation 


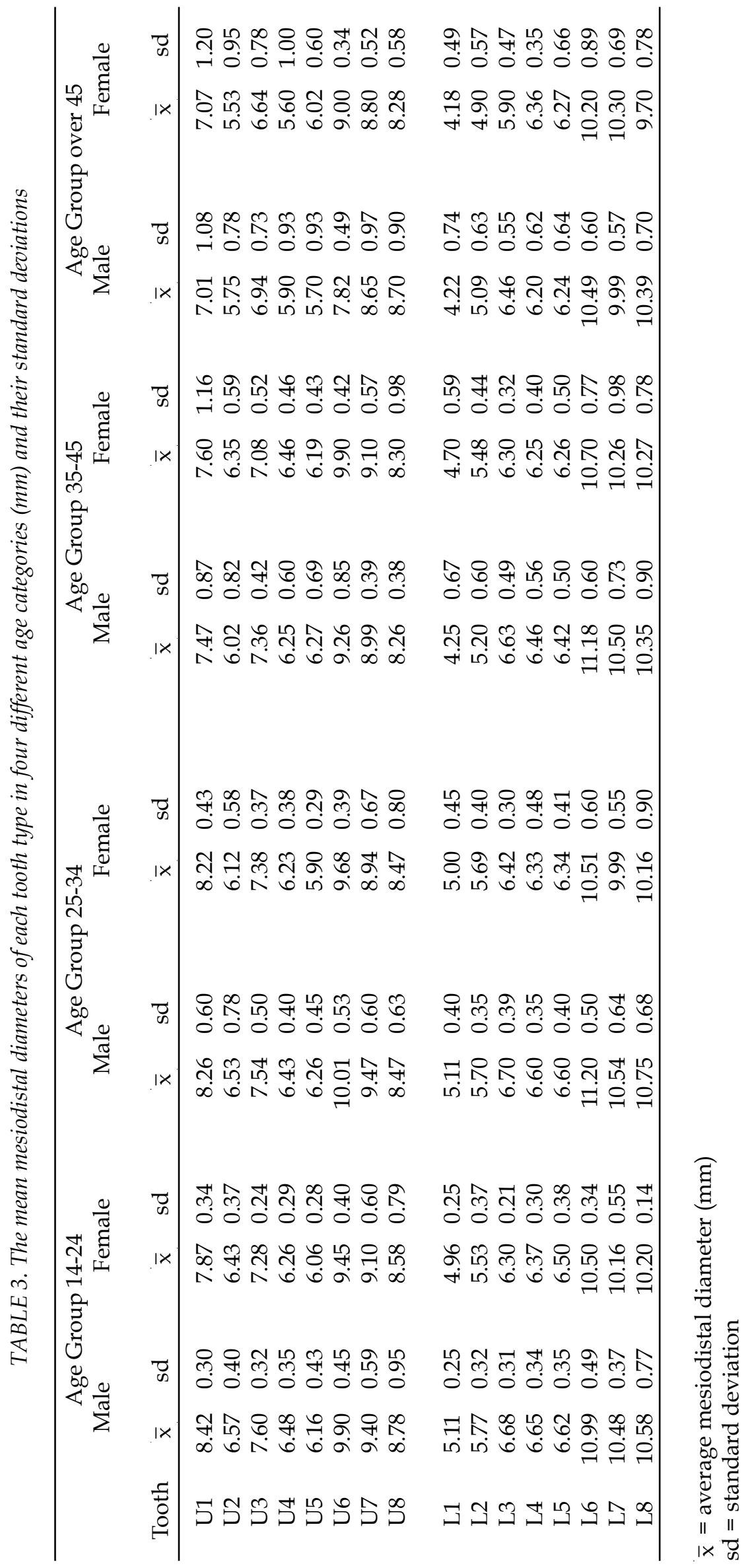




\section{RESULTS}

Since there was no significant difference for individual tooth type between the findings from different sides of the mouth, right and left side measurements were pooled in these results.

In Table 2 the means and standard deviations of the mesiodistal crown diameters of each tooth type for age group 1, the 14-24 year olds, are given for the sample measured by examiner 1 and that measured by examiner 2. For almost all tooth types the measurements differed by less the $0.2 \mathrm{~mm}$ between the two examiners. The mean mesiodistal measurements for male teeth are larger than for females for all tooth types and this difference is statistically significant for upper central incisors, canines, first and second molars and for lower lateral incisors, canines, first and second molars.

In Table 3 the means and standard deviations of the mesiodistal crown diameters of each tooth type in the four different age categories determined by examiner 2 are given. The standard deviations of the means tend to be larger in the older age groups. These standard deviations are also greater for posterior compared to anterior teeth. However, they are similar for males and females in each age category. These "raw" figures show a pattern of decreasing tooth size over the four age groups, this trend being greater in males.

To investigate these changes further in Table 4 the differences between mean mesiodistal crown diameters at ages 14-24 years and over 45 years are given. For all tooth types except the lower second molar in females, the mesiodistal diameter is smaller in age group 4 than in age group 1. Using a two sample t-test this difference is statistically significant to varying degrees for all tooth types except the upper second premolar, the upper third molar and the lower first and third molars (Table 4). The greatest reductions were in the upper and lower incisors, the upper canines and upper first molars.

In Table 5 the outcome of the multiple regression analysis is given. This confirms the decrease in mesiodistal crown diameters with increasing age. This decrease was significant with this analysis as indicated by the $\mathrm{T}$ ratio for the age group coefficient, in all upper teeth except the second premolar (U5) and third molar (U8) and all the lower teeth except the molars (L6, L7

TABLE 4. Difference between the average mesiodistal crown diameters ( $\mathrm{mm}$ ) at age group 1 and age group 4 for males (column 1), females (column 2), and pooled male and female data (column 3) ${ }^{1}$

Difference between mean mesiodistal crown diameters for age group 1 and age group 4

\begin{tabular}{cllccc}
\cline { 3 - 4 } Tooth & Male & Female & $\begin{array}{c}\text { Pooled } \\
\text { sexes }\end{array}$ & $\begin{array}{c}\text { Difference } \\
\text { between male } \\
\text { and female }\end{array}$ & $\begin{array}{c}\text { Regression } \\
\text { equation } \\
\text { estimation }\end{array}$ \\
\hline U1 & $1.41^{* * *}$ & $0.81^{*}$ & $1.11^{* * *}$ & +0.60 & 1.25 \\
U2 & $0.81^{* *}$ & $0.90^{*}$ & $0.86^{* * *}$ & -0.10 & 0.80 \\
U3 & $0.67^{* *}$ & $0.64^{* *}$ & $0.65^{* * *}$ & +0.03 & 0.66 \\
U4 & 0.53 & $0.62^{*}$ & $0.65^{* *}$ & -0.08 & 0.47 \\
U5 & 0.46 & 0.03 & 0.24 & +0.43 & 0.20 \\
U6 & $2.12^{* * *}$ & $0.44^{*}$ & $1.28^{* * *}$ & +1.68 & 0.89 \\
U7 & 0.76 & 0.32 & $0.54^{*}$ & +0.45 & 0.46 \\
U8 & 0.08 & 0.30 & 0.19 & -0.22 & 0.27 \\
L1 & $0.89^{* * *}$ & $0.78^{* * *}$ & $0.84^{* * *}$ & +0.11 & 0.96 \\
L2 & $0.68^{* * *}$ & $0.58^{* *}$ & $0.63^{* * *}$ & +0.10 & 0.69 \\
L3 & 0.22 & $0.38^{* *}$ & $0.30^{*}$ & -0.16 & 0.30 \\
L4 & $0.44^{*}$ & 0.01 & $0.22^{*}$ & +0.43 & 0.24 \\
L5 & $0.38^{*}$ & 0.24 & $0.31^{*}$ & +0.14 & 0.34 \\
L6 & 0.50 & 0.33 & 0.41 & +0.17 & 0.22 \\
L7 & $0.49^{*}$ & -0.18 & 0.16 & +0.67 & 0.11 \\
L8 & 0.19 & 0.48 & 0.33 & -0.29 & 0.36 \\
\hline
\end{tabular}

${ }^{1}$ The difference between male and female difference is also given in (column 4). The mesiodistal tooth reduction as estimated by the regression equation has also been included for comparative purposes (column 5)

*Significant at $5 \%$ level

**Significant at $1 \%$ level

***Significant at 0.1 level 
TABLE 5. T-values of multiple regression analysis ${ }^{1}$

\begin{tabular}{cccccc}
\hline Tooth & Female-Male & Age group & Tooth & Female-Male & Age group \\
\hline U1 & NS & $-6.50^{*}$ & L1 & NS & $-7.88^{*}$ \\
U2 & NS & $-4.90^{*}$ & L2 & NS & $-6.53^{*}$ \\
U3 & $3.29^{*}$ & $-5.89^{*}$ & L3 & $6.36^{*}$ & $-3.55^{*}$ \\
U4 & NS & $-3.42^{*}$ & L4 & $2.81^{*}$ & $-2.49^{*}$ \\
U5 & NS & & L5 & $2.03^{*}$ & $-3.17^{*}$ \\
U6 & NS & $-4.86^{*}$ & L6 & $5.68^{*}$ & NS \\
U7 & $2.55^{*}$ & $-2.72^{*}$ & L7 & $3.37^{*}$ & NS \\
U8 & NS & & L8 & $2.73^{*}$ & NS \\
\hline
\end{tabular}

${ }^{1}$ Where $t$ value not quoted, value was below 2 and was not significant

and L8).

The multiple regression analysis also indicates the tendency for female teeth to be smaller than male was significant, as shown by the T ratio for the sex coefficient, for all lower teeth except the incisors and for the upper canine and second molar.

The total reduction in mesiodistal diameter for each tooth from age group 1 (14-24 years) to age group 4 (over 45 years) can be estimated by multiplying the age group coefficient by three. The totals estimated by this method are given in Table 4 . The totals for each tooth from the last column in Table 4 can then be added together and this figure doubled, to estimate a total upper and lower arch length reduction of $10 \mathrm{~mm}$ and $6.4 \mathrm{~mm}$, respectively.

An alternative way of using the data to estimate the total reduction in mesiodistal tooth diameter is to subtract the average measurements of teeth in age group 4 from those in age group 1 . Table 4 also gives the results obtained by this second method. The table confirms that the reduction in diameter is usually greater in males. When the average of the male-female difference is compared with the reduction estimated from the regression equation, the two estimations are within $0.15 \mathrm{~mm}$, except for the upper lateral incisor, upper first molar and lower first molar, where they are greater when estimated by the second method, and the upper central incisors, where they are smaller. The total upper and lower arch reductions estimated by the second method are $10.9 \mathrm{~mm}$ and $6.4 \mathrm{~mm}$, respectively.

\section{DISCUSSION}

It was important that the gender of the skeletons was determined prior to tooth measurement, because if, for example, a far larger number of female teeth were included in a particular age group, measurements would tend to be reduced due to the sexual dimorphism of tooth size. This would also tend to distort the estimates of mesiodistal attrition gained by comparing dimensions. It is possible that this may have occurred in some previous studies where the sex of the skeletal remains was not specified. Mortality amongst young females in earlier populations was high, possibly from childbirth, but also from neglect compared to boys (Farwell and Molleson, 1993). Therefore skulls from such populations where the third molar is just erupting may more frequently be female.

Small numbers of certain tooth types were included in age group 4, age over 45 years, because only a limited number of skulls were available for selection and many of these did not satisfy the criteria for inclusion. Whilst caution is necessary in interpreting results from small numbers, the multiple regression analysis did take this into account.

The finding that measurements for mesiodistal crown diameters for the youngest age group, 14-24 year, gave closely similar results for the two samples and the two operators suggests that the data obtained are reliable. While some mesiodistal wear may have occurred even in this group it is unlikely to have yet made any significant differences to those dimensions. Supporting this contention there were no significant differences between age groups 1 and 2 .

In the present study there was a statistically significant change in diameter between age groups 1 and 4 (Table 4). This reduction in mesiodistal size is associated with marked occlusal attrition in age group 4, and can be ascribed to approximal attrition. In a sample of 97 mediaeval Swedish skulls Lysell $(1958 a, b)$ showed a comparable reduction in mesiodistal tooth diameters between "juvenile" and "mature" age groups.

Also in the present study it was seen that these reductions were greater in some tooth types than others (Table 4). Similarly Lysell's (1958a,b) results show different interproximal attrition in different tooth types. In Lysell's $(1958 a, b)$ study the teeth showing the greatest approximal wear are the upper and lower incisors and the upper first molars. While these teeth were also markedly affected in the present study, so also were the upper and lower canines and, to a lesser extent the premolars (Table 4). As an explanation for 
this pattern and therefore time in occlusion may be considered. However, against this suggestion is the fact that in the present study and Lysell's $(1958 a, b)$ the lower first molars were not significantly affected, and in the present study the later erupting canines were more affected. Therefore, considering the patterns shown in Tables 4 and 5, it seems probably that a more complex etiology for the attrition must be considered as well as time lapsed since eruption.

There are a series of factors affecting attrition (Hillson, 1996). These include masticatory forces, non-chewing parafunctions, the use of teeth as tools and the nature of the diet. The combined effects of lateral, anteroposterior and axial forces during mastication result in complex movements of one approximal surface against another. The magnitude and duration of these masticatory forces is added to by such non-chewing use as bruxism, which may occur in some individuals when asleep or unconsciously whilst awake. In addition a tough fibrous diet required heavy prolonged mastication and the abrasiveness of diets in early populations containing barley or rye was increased by the incorporation of grit from hand grinding using stone querns.

The people of Poundbury had large jaws and edge to edge occlusion; they ate coarse food that required prolonged chewing (Farwell and Molleson, 1993). They probably had an agricultural life style fulfilling the criteria of Hinton (1981) with cereals as the predominant element in the diet. Interesting facets arising from the present study are the sex difference in the degree of approximal attrition and the pattern across tooth types, which contrasts with that for occlusal attrition for this population described by Whittaker et al. (1982).

For the mesiodistal crown diameters of all tooth types in age group 1, female measurements were smaller than male measurements (Table 2). However in age group 4 , over 45 years, only the lower canine is statistically significantly smaller in the female and for several tooth types, namely the upper central incisor, second premolar and first and second molars and the lower premolars and second molar, the sex difference is reversed (Table 3). These findings suggest that males exhibit greater approximal attrition than females overall, although the extent of this difference varies between the different tooth types (Tables 4 and 5).

\section{CONCLUSIONS}

In these Romano-Britons there is a progressive pattern of approximal attrition with increasing age. This attrition was greater in males than females and varied among different tooth types. The estimated total arch length reduction was comparable for the two methods used and was slightly greater than some other historical populations. The etiology of the attrition is multifactorial and reflects the lifestyle of this population. This study has also illustrated the importance of sampling and establishment of a baseline group for comparisons.

\section{ACKNOWLEDGEMENTS}

We are grateful for the support of Theya Molleson and for access to the material at the British Museum (Natural History). Also, David Whittaker was generous with his advice and encouragement.

\section{LITERATURE CITED}

Brook AH. 1984. A unifying aetiological explanation for anomalies of human tooth number and size. Arch Oral Biol 29:373-378.

Brothwell DR. 1963. Digging up bones. London: Trustees of the British Museum, p 57-70.

Brothwell DR. 1989. The relationship of tooth wear to aging. In: Iscan MY, editor. Age markers in the human skeleton. Springfield: CC Thomas, p 303-316.

Farwell DE, Molleson TL. 1993. Excavations at Poundbury 1966-80, Vol 2: The cemeteries. Dorchester, UK: Friary Press, p 171-186.

Hillson S. 1996. Dental anthropology. Cambridge: Cambridge University Press, p 231-253.

Hinton RJ. 1981. Form and patterning of anterior tooth wear among aboriginal human groups. Am J Phys Anthropol 54:555-564.

Keiser JA. 1990. Human adult odontometrics. Cambridge: Cambridge University Press, Cambridge, $p$ 10-12.

Lysell L. 1958a. A biometric study of occlusion and dental arches in a series of medieval skulls from Northern Sweden. Acta Odontol Scand 16:177-180.

Lysell L. 1958b. Quantitative and qualitative determination of attrition and the ensuing tooth migration. Acta Odontol Scand 16:267-293.

Miles AEW. 1963a. The dentition in the assessment of individual age. In: Brothwell DR, editor. Dental anthropology. Oxford: Pergamon Press, p 191-209.

Miles AEW. 1963b. Dentition in the estimation of age. J Dent Res 42:255-263.

Molnar S. 1971. Human tooth wear, tooth function and cultural variability. Am J Phys Anthropol 34:175190.

Moorrees CFA, Yen PK. 1957. Mesiodistal crown diameters of the deciduous and permanent teeth in individuals. J Dent Res 36:39-47.

Solheim T. 1996. Degeneration in dental hard tissues and pulp. In: Alt KW, Rosing FW, Teschler-Nicola M, editors. Dental anthropology: Fundamentals, limits and prospects. New York: Springer Wein, p 469-478.

Whittaker DK, Parker JH, Jenkins C. 1982. Tooth attrition and continuing eruption in a Romano-British population. Arch Oral Biol 27:405-408. 